\title{
A importância da Família como expressão dos Direitos Humanos e as suas interseç̧ões com a Educação e a Escola na Educação Básica brasileira.
}

\author{
Guilherme de Almeida Prazeres ${ }^{1}$
}

\section{RESUMO:}

O artigo busca refletir sobre as diferentes concepções de Família, tanto em sua constituição histórica quanto em sua formação cultural e social atual, com ênfase na garantia legal e institucional do "direito familiar" no Estado de Direito do Brasil. Analisa as transformações históricas da Família e destaca sua importância sociológica, psicológica e cultural, para a humanização e a formação da dignidade de cada pessoa. Trata-se de um estudo bibliográfico e histórico, com um resgate institucional e conceitual, seguido de uma interpretação das interrelações entre Famílias e Escolas, postas para a promoção do sucesso escolar e cultural das crianças e dos adolescentes. Aponta a Educação como um importante campo de articulação entre as esferas familiares e a sociedade, acentuando a importância de estudos que vinculem a questão da Família como Direito Humano inalienável.

Palavras-Chave: Família. Educação. Direitos Humanos.

\begin{abstract}
:
The article seeks to reflect on the different conceptions of the Family, both in their historical constitution and in their current cultural and social formation, with an emphasis on the legal and institutional guarantee of "family law" in the rule of law in Brazil. It analyzes the historical transformations of the Family and highlights its sociological, psychological and cultural importance, for the humanization and the formation of the dignity of each person. This is a bibliographic and historical study, with an institutional and conceptual rescue, followed by an interpretation of the interrelationships between Families and Schools, put forward to promote the school and cultural success of children and adolescents. It points to Education as an important field of articulation between family spheres and society, emphasizing the importance of studies that link the issue of the Family as an inalienable Human Right.
\end{abstract}

Keywords: Family. Education. Human rights.

\footnotetext{
${ }^{1}$ Pesquisador do Grupo de Estudos em Filosofia e Educação PAIDEIA, membro do INPPDH.
} 


\section{RESUMEN:}

El artículo busca reflexionar sobre las distintas concepciones de la Familia, tanto en su constitución histórica como en su actual formación cultural y social, con énfasis en la garantía legal e institucional del "derecho de familia" en el estado de derecho en Brasil. Analiza las transformaciones históricas de la Familia y destaca su importancia sociológica, psicológica y cultural, para la humanización y la formación de la dignidad de cada persona. Se trata de un estudio bibliográfico e histórico, con un rescate institucional y conceptual, seguido de una interpretación de las interrelaciones entre Familias y Escuelas, planteadas para promover el éxito escolar y cultural de niños y adolescentes. Señala a la Educación como un importante campo de articulación entre los ámbitos de la familia y la sociedad, enfatizando la importancia de los estudios que vinculan el tema de la Familia como Derecho Humano inalienable.

Palabras clave: Familia. Educación. Derechos humanos.

\section{Introdução}

Buscaremos desenvolver uma sucinta investigação histórica, de base jurídica e cultural, para caracterizar a identidade institucional da Família e suas diversas formas de representação na sociedade atual e em épocas distintas. Nosso intento será de caracterizar a Família como uma instituição social em acentuadas transformações, reforçando seu caráter de transitoriedade entre as esferas particulares e a sociedade. Analisaremos a importância da relação entre as Escolas e as Famílias dos educandos, de modo que possam sentir-se acolhidos e integrados ao campo social a partir de suas vivencias e de suas culturas familiares. A família, então, constitui-se como um direito humano inalienável, e a sociedade que alinha-se com a preservação da dignidade da vida terá que garantir os direitos familiares como Direitos Humanos fundamentais.

A palavra família vem do latim famulus, termo que representava o grupo de servos domésticos, aqueles que residiam na mesma casa que o senhor. Dos gregos derivam duas compreensões de família muito distintas. Para Platão (FLANDRIN, 1976), a família constituía um genos (linhagem, raça, dinastia), enquanto para Aristóteles é oikia ou oikos (comunidade) que 
serve de base para a pólis (ARISTÓTELES, 1998). E o que quer dizer "família" no Brasil de 2020?

As respostas mais imediatas poderiam limitar-se a descrever, sem medo de errar, que a família é uma instituição composta por pai, mãe e filhos, pois essa é a vontade de Deus. Encontraríamos aqui uma definição tradicional de Família. Haveria, também, quem pudesse relacionar os inúmeros tipos de famílias que crescem nos lares brasileiros, entre elas, famílias homoafetivas, famílias poliamorosas, famílias monoparentais e tantas outras possibilidades de arranjos humanos. E haveria, ainda, quem pudesse dizer que as famílias estão desaparecendo ou acabando, em razão do crescente individualismo. Muitas são as possibilidades de respostas e todas elas têm suas razões e suas contradições. Não se trata de uma tarefa simples refletir sobre este tema.

Preliminarmente, é preciso abordar a constituição familiar em decorrência da consanguinidade, ao menos no âmbito da família nuclear. Tal assertiva ampara-se em uma questão absolutamente prática: a necessidade de que os genitores criem as crianças que geram e de que essas crianças, quando adultos, amparem seus genitores idosos. Não se considera, nesse quesito, aspectos subjetivos como o afeto, a vontade, a liberdade, o desejo de relativizar vínculos e obrigações. Essa primeira forma de compreender a família tem como justificativa os vínculos de consanguinidade, mas só se materializa a partir da perspectiva da tradição, de nossa cultura e da nossa legislação.

Talvez essa concepção de família deixe de existir se eventualmente o Estado, ou alguma outra forma de organização, puder responsabilizar-se integralmente pelo cuidado com crianças e idosos. Entretanto, não nos parece ser algo viável a curto e médio prazo, considerando que ainda hoje o respaldo tanto do Estado quanto de um imenso número de famílias é insuficiente para atender tais sujeitos. Proteger a Família como Direito implica, necessariamente, a proteção das crianças (LEI 8.069/90) e dos idosos (LEI 10.741/2003). 
No entanto, a família também pode ser compreendida a partir de outros aspectos, como o afeto, o amor, o carinho e o desejo de cuidar, que, em um primeiro momento, podem parecer todos subjetivos, mas cuja materialidade se dá de modo tangível, como veremos mais adiante. Sobre essa concepção de família que pretendemos representar usaremos como paradigma a obra do prof. Charles Taylor, expoente filósofo e defensor da Ética da Autenticidade.

$\mathrm{O}$ prof. Taylor ensina que não podemos compreender $\mathrm{o}$ individualismo, típico de nossa Era, como um desejo egoísta, hedonista ou narcisista (pois se assim o fosse, não haveria mais esperança para nossa espécie), mas sim como um desejo por encontrar sua própria autenticidade, ou seja, aquilo que torna cada um de nós singulares (TAYLOR, 2011).

A partir do final da década de 1970, início da década de 1980, o desmantelamento de regimes políticos e discursos capazes de explicar o todo da sociedade e de indicar, ainda que pautados pela utopia, nortes a serem seguidos, teve como uma de suas consequências a perda de perspectiva de superações coletivas possíveis. Somada a isso, a crise geral de autoridade que começou a perpassar diversos outros campos da sociedade, tais como a religião, a escola e a família, colaborou para o surgimento de um panorama no qual a crise de referências sólidas fez com que as pessoas passassem a se voltar apenas para suas próprias existências; segundo Taylor, por receio de não haver outra chance, e não por egoísmo (TAYLOR, 2011). Kundera é um exemplo de apreensão artística do sentimento de mudança que pairava:

Não existe meio de verificar qual é a boa decisão, pois não existe termo de comparação. Tudo é vivido pela primeira vez e sem preparação. Como se um ator entrasse em cena sem nunca ter ensaiado. Mas o que pode valer a vida, se o primeiro ensaio da vida já é a própria vida? É isso que faz com que a vida pareça sempre um esboço. No entanto, mesmo "esboço" não é a palavra certa porque um esboço é sempre um projeto de alguma coisa, a preparação de um quadro, ao passo que o esboço que é a nossa vida não é o esboço de nada, é um esboço sem quadro. (KUNDERA, 2017) 
O medo de que nossas existências sejam desprezadas pela história como um esboço de uma obra que nunca se concretiza seria causa desse narcisismo radical lido simplesmente como um individualismo exacerbado (TAYLOR, 2011). A partir disso, teríamos nos esquecido que só somos autênticos em relação a algo ou alguém, que a nossa singularidade não se expressa de maneira solitária e que para que nossa existência seja verdadeiramente única, nossas ações têm de nos vincular a algo significativo para a história, para a natureza, para as obrigações da cidadania, para o sagrado, ou para as necessidades de outros seres humanos (TAYLOR, 2011). Na medida em que as pessoas querem sentir-se especiais, voltaremse para uma autorrealização voluntariosa e individualista é autoestultificante.

A partir desse panorama, a compreensão de Charles Taylor sobre nossa sociedade mostra-se plenamente apta a nos servir de paradigma para uma concepção de família, que em nossa visão, atende aos desejos singulares de cada sujeito ao mesmo tempo que vincula-se a algo significativo como descrito no parágrafo anterior. A família não se constitui por relacionamentos interpessoais vulgares, mas por relacionamentos significativos e nesse contexto ser significativo refere-se a cumprir com suas obrigações de cidadania (obrigações legais) e de auxílio com nossos pares humanos, visando o desenvolvimento social, ético, intelectual e econômico por meio de auxílio mútuo em um ambiente que priorize a amorosidade. No entanto, a família não foi sempre assim.

\section{Breve excurso histórico sobre a formação das famílias.}

Há cerca de 350.000 anos, surgia, no leste da África, a espécie Homo sapiens. A partir desse momento, levamos 300.000 anos para desenvolver a linguagem, a música e outras expressões culturais que viriam a ser transmitidas de geração em geração. Vivíamos em pequenos grupos nômades de caçadores-coletores, nos espalhando pelo planeta, até que há cerca de 10.000 anos a agricultura, a domesticação de animais e o domínio de objetos metálicos, conquistas da chamada "Idade do Cobre", 
possibilitaram a criação de assentamentos permanentes que seriam o embrião da civilização.

Desde que a dimensão da cultura passou a existir como aspecto imanente de nossa natureza humana e a transmissão do aprendizado passou a ser determinante como fator de sobrevivência e desenvolvimento individual e coletivo, pudemos entender a existência desses dois universos que, remotamente, podemos chamar de ancestrais da Família e da Educação como determinantes no processo de humanização da espécie.

A ancestralidade da família funda-se há cerca de 10.000 anos, quando os assentamentos se estabelecem e os grupos humanos reconhecem uns aos outros como equivalentes e aptos para uma aliança gerando assim sociedades, associações primitivas sem as quais não seria possível a consolidação embrionária da família e da parentalidade (LEVI-STRAUSS, 1984). Resgatar as transformações da família ao longo da história nos auxiliará a compreendê-la não como algo "natural", mas sim como fenômeno histórico e cultural. A percepção de que as famílias refletem determinado recorte histórico e cultural nos ajuda a compreender a aparente desordem familiar da atualidade (ROUDINESCO, 2003) e nos ajudará a estabelecer relações com a escola na contemporaneidade.

Tão antiga quanto a própria família é a proibição taxativa do incesto entre pais e filhas e mães e filhos, o que parece ser universal, ou seja, não se restringe a um tempo ou a uma região específica do globo. Tal proibição potencializou a troca sobretudo de mulheres (MAUSS, 1950 e LEVISTRAUSS, 1984) e, com isso, possibilitou a consolidação de laços entre sujeitos além da consanguinidade e a partir de duas famílias, uma fornecendo um homem e outra uma mulher, unem-se e formam uma terceira família e assim sucessivamente (HÉRITIER, 1998). Esse movimento foi determinante para o desenvolvimento social de nossa espécie, o que por si já determinaria o caráter cultural da família humana, pois nossa procriação passa a ter uma ordenação articulada por uma norma.

No Império Romano, a família já se constituía em termos mais reconhecíveis a nós. Tratava-se da união de duas pessoas que buscavam 
gerar descendência com a finalidade de transmitir bens e posição social em uma organização política estratificada (ROUDINESCO, 2003), representando o que viríamos a chamar de família extensa.

O matrimônio, no modelo que hoje reconhecemos como hegemônico no Ocidente, também foi criado no Império Romano como instituição social e política em um contexto no qual a autoridade patriarcal representava transposição da monarquia para o cotidiano doméstico (ARIÈS e DUBY, 2009), no qual o pai reinava sobre o corpo da família (ROUDINESCO, 2003). Os arranjos de casamento nessa época não consideravam relevante a relação afetiva ou o interesse sexual entre os nubentes, que eram, na maioria das vezes, ainda crianças. Com todas as contradições que esse modelo possa carregar, os arranjos por aliança foram determinantes no processo de evolução da sociedade como veremos mais adiante.

Nessa família que já se esboçava "tradicional", o sangue não importava tanto, aparentemente havia a percepção de que os cidadãos romanos, detentores de direitos, não tivessem filhos naturais, pois o vínculo familiar só se estabelecia a partir de um ritual dramático, fazendo prevalecer o pater (aquele que designa a si mesmo como pai) sobre o genitor (filiação biológica), em uma clara alusão ao poder do homem (razão) sobre as coisas da natureza, como a mulher (passionalidade) (ROUDINESCO, 2003). Nesse ritual, chamado de tollere liberum ou suscipere liberum, colocava-se o recém-nascido aos pés de quem indicativamente seria o pai e cabia a este levantar a criança do chão e erguê-la em seus braços (SHAW, 2001), simbolicamente assumindo a paternidade, ou enjeitá-la, o que implicaria na condenação dessa criança ao abandono familiar e recorrentemente à morte, caso não fosse adotada.

$\mathrm{Na}$ mesma época, as tradições egípcia, germânica e judaica diferenciavam-se das culturas romana e grega por não rejeitarem nenhum filho. Assim, todas as crianças eram criadas (ARIÈS e DUBY, 2009), o que nos indica que a concepção de família não é apenas histórica, ou seja, não se vincula a apenas um recorte temporal, mas também a uma determinada cultura. Tal fato reforça nossa afirmação de que a família é imanentemente 
instituição social histórico-cultural e não natural. A força do caráter biológico atribuído à família só ganharia importância na Idade Média, por razões religiosas que determinariam a cultura de gerações, como veremos a seguir.

Durante a Idade Média, o casamento deixou de ser uma outorga estatal e passou a ser um sacramento religioso. Assim como no Império Romano, a família permanece sendo instituição, criadora e criatura de um recorte histórico e cultural, pois enquanto o monarca precisaria da chancela papal para ter sua autoridade real reconhecida, a família careceria da benção litúrgica para se legitimar e constituir, vinculando-se, assim, ao sagrado, de modo indissolúvel. Nessa realidade, apenas as crianças nascidas dentro dessa relação sacramentada eram consideradas parte da família (ARIÈS e DUBY, 2009).

A cristandade trouxe consigo a simbologia de que a paternidade, ao contrário do que enunciava o Direito Romano, não é desdobramento da vontade do pai, mas da vontade de Deus (ROUDINESCO, 2003). Nesse contexto, o filho, nascido a partir da relação marital sacramentada pela igreja, constituía-se como herdeiro do sangue (aspectos biológicos) e do sobrenome do pai (patrimônio e posição social). Pater e genitor se fundem sob a égide da paternidade, o que não ocorria com os filhos da bastardia resultantes da infidelidade do homem. A ideia de que a mulher não seria fiel ao homem era inconcebível por colocar em xeque toda a lógica cristã que dali decorria. Em razão disso, o controle da mulher pelas leis de Deus e do matrimônio eram determinantes (ROUDINESCO, 2003), pois como teria professado Jean Bodin em 1560:

Assim como a religião, a família deve perpetuar a soberania do pai, e só pode consegui-lo sob a condição de se libertar da influência da feitiçaria. Pois a feiticeira, verdadeiro paradigma da desmedida feminina, desafia permanentemente sua autoridade opondo-lhe uma força maléfica, sexual, sedutora, 'ateia', fonte de sedição e de devassidão. (ROUDINESCO, 2003) 
Ainda na Idade Média, a sensualidade e a paixão eram consideradas aberrações incompatíveis com a sacralidade da família enquanto o amor deveria ser voltado unicamente para Deus (HIGHWATER, 1992). Declarar ou sentir amor por um mortal era sinal de blasfêmia ao trazer para o universo terreno sentimento da ordem do sagrado.

Já na Idade Moderna, a família passou a ser, idealmente, desdobramento do amor romântico (não confundir com Romantismo), da reciprocidade de sentimentos e de desejos sexuais. O casamento funda-se no amor e tende a manter-se em prol do "aumento do patrimônio comum, da responsabilidade de serem pais e das obrigações sociais a base da continuação do casamento" (HIGHWATER, 1992). Tal afirmação pode parecer um tanto quando áspera quando feita de modo descontextualizado, mas não podemos nos esquecer que até o final do séc. XIX a maior parte dos casamentos da aristocracia era planejado para a geração de herdeiros enquanto os filhos das famílias do campo e em indústrias domésticas serviam como mão de obra não remunerada.

A novidade mais significativa do ponto de vista social talvez tenha sido a divisão do trabalho entre o casal, o que implicaria na necessidade de que o Estado assumisse para si a educação das crianças que agora eram vistos como sujeitos (PERROT, 2009). Entre os séculos XVI e XVIII, o núcleo pai-mãe-filho(s) ganharia força e se destacaria do que até então era compreendido como a família (grupo que incluía a parentela, agregados, amigos e criadagem doméstica) e vinha sendo a expressão do patriarcado e de uma comunidade hierarquizada que representava o domínio do senhor em relação ao seu escravo, da associação do marido e da esposa e do vínculo entre o pai e os filhos (ROUDINESCO, 2003). Sem essas comunidades, haveria ameaça de anarquia, o que inviabilizaria o desenvolvimento da sociedade.

Na Modernidade, reconhecida como a Era dos Direitos, a Família seria positivada na Declaração Universal de Direitos Humanos de 1948. O artigo 16 da Declaração Universal de Direitos Humanos (DUDH) anunciava uma relação de igualdade entre homens e mulheres, algo que ainda hoje não 
se materializou e continua sendo objeto de advocacia da Organização das Nações Unidas ${ }^{2}$.

Chegamos à década de 1960 com todas as suas idiossincrasias e uma nova alteração na organização familiar acontece. A justificação para a formação e manutenção das famílias a partir do componente afetivo e sexual que se iniciou na Idade Moderna intensifica-se e torna-se o principal argumento como constituidor familiar. Pela primeira vez, a família deixa de ser representação de um poder acima dos indivíduos, seja ele estatal, seja religioso, seja patriarcal, desatrelando-se de uma organização superior e concretizando-se como manifestação pura dos desejos individuais (ROUDINESCO, 2003).

\section{As articulações entre Famílias e Educação e Escolas.}

Nesse ambiente em que desejos individuais predominam indistintamente, por que é tão importante debatermos a Família no campo da Educação? O trabalho de referenciais da Educação como Piaget (1984), Vygotsky (1998b), Wallon (in Galvão, 1995), Bronfenbrenner (2011) e Paulo Freire (em toda sua obra) destacam a importância da afetividade no processo de humanização do ser humano desde a primeira infância, quando já iniciamos o desenho de nossas próprias histórias a partir, principalmente, dos estímulos recebidos dos microssistemas família e escola:

O ponto de partida dessa discussão é o fato de que o aprendizado das crianças começa muito antes de elas frequentarem a escola. Qualquer situação de aprendizado com a qual a criança se defronta na escola tem sempre uma história prévia. [...] De fato, aprendizado e desenvolvimento estão interrelacionados desde o primeiro dia de vida da criança. (VIGOTSKY, 1998a)

Não nos parece haver controvérsia entre pesquisadores e familiares de estudantes sobre a importância da família no processo de aprendizagem das crianças, adolescentes e jovens ainda que existam grandes dúvidas de como essa aproximação possa se dar de modo que seus processos e

\footnotetext{
${ }^{2}$ Vide Objetivo de Desenvolvimento Sustentável 5 - Alcançar a igualdade de gênero e empoderar todas as mulheres e meninas.
}

Filos. e Educ., Campinas, SP, v.12, n.2, p.1193-1211, maio/ago. 2020 - ISSN 1984-9605 
resultados sejam os mais benéficos para os sujeitos envolvidos e por conseguinte, para a sociedade.

A investigação sobre a importância dos ambientes familiares, realizada nos últimos 25 anos, mostra que as crianças têm vantagens quando as suas famílias apoiam e encorajam a educação [...]. Os estudos mostram que o envolvimento das famílias na educação pode ajudar a compensar a falta de recursos familiares e os benefícios para os estudantes com menores recursos podem ainda ser maiores do que para os restantes. (EPSTEIN, 1992).

A relação entre família e escola vai além dos benefícios para os alunos, multiplicando-se em todo o universo familiar e social das crianças e impactando positivamente, de modo contundente, toda a comunidade conexa ao aluno:

O envolvimento entre família e escola não só contribui com todo o processo educacional como também para a melhoria dos ambientes familiares, possibilitando uma maior compreensão do processo de crescimento e, portanto, de aprendizagem de crianças e jovens. (DESSEN, 2005).

Quando a realidade se impôs com a pandemia de COVID-19 e as famílias passaram a atuar como intermediadores da educação em suas residências a partir das orientações dos professores, das escolas e redes de educação municipais e estaduais, ficou a premência dessa relação, especialmente quando o futuro da escola como a conhecemos permanece indefinido.

Nos referimos à família como intermediadores, para que não haja confusão com o papel de mediador escolar que ganhou destaque a partir da Declaração de Salamanca de 1994 (MOUSINHO, 2010), que fixou princípios, políticas e práticas na área das necessidades educativas especiais para a inclusão. O papel de intermediador desempenhado pelas famílias mostrou-se determinante para a continuidade do processo de aprendizagem no ano de 2020, pois muitas vezes, ainda que possuam certa autonomia, as 
crianças não têm autogoverno o suficiente de disciplina necessária para o acompanhamento das aulas de forma remota nas plataformas digitais.

Já no processo de pesquisa para o presente artigo aos bancos de dados Scielo, Capes e BDTD, constatamos que o tema "família e escola" enseja debates, mas que a produção acadêmica raramente dialoga com as famílias. Ainda que Família e Escola existam a partir de uma relação cíclica e de integralidade uma com a outra a ponto de tal vínculo estar positivado em nossa Carta Magna (art. 205), poucos estudos brasileiros preocupam-se em realizar uma investigação robusta e metodologicamente acurada da relação família e escola no meio acadêmico. Muitos educadores entendem que caberia às famílias procurarem as escolas de forma espontânea (SOUZA, 2017) e não apenas irem até a escola quando convocados para tratar de alguma questão de comportamento ou receber o boletim com as notas das crianças.

Entretanto, hoje, parece haver grandes discrepâncias entre os valores familiares e escolares, produzindo certa insatisfação em ambos os contextos, o que, por sua vez, pode desestimular a participação e o envolvimento dos pais na escola. Se por um lado a escola subestima o papel dos pais na educação formal dos seus filhos, os pais demonstram passividade face à escola, esperando que ela resolva, sozinha, as dificuldades de aprendizagem e a falta de motivação dos alunos, bem como problemas comportamentais, dentre os quais a violência. (POLONIA e DESSEN, 2005)

Nesse sentido, a escola enquanto locus educativo de transmissão de conhecimento historicamente acumulado, não precisa desvirtuar-se de seu propósito constitutivo para criar subterfúgios para a aproximação com a família, mas precisa ser criativa para romper as barreiras estabelecidas que separam a escola da comunidade que a cerca. Nas últimas décadas algum avanço foi feito e a família passou a participar mais da vida escolar das crianças, mas não da forma esperada pelos educadores, pois os familiares especializaram-se em protestar, ora como forma de proteção dos filhos, ora como modo de se revoltar contra a autoridade que a escola representa 
(THIN, 2006), mas poucos avanços foram concretizados quando se pensa em um trabalho coletivo entre esses sujeitos.

Massivamente, as pesquisas encontradas apontam para a importância do fortalecimento da relação dialógica e democrática família-escola ao passo que não investiga, não atua no sentido de aproximar, efetivamente, essas duas instituições sociais humanas em prol da Educação, da Cidadania, da Emancipação, da Igualdade de Gêneros, das Crianças, Jovens e Adolescente (POLONIA e DESSEN, 2005), fato esse notado por alguns pesquisadores mais sensíveis.

A professora Oralda Adur Souza (2017), pesquisadora da educação, realizou, em sua tese de doutoramento na UFPR intitulada "Família-escola e desenvolvimento humano: um estudo sobre atitudes educativas familiares" (2017), minuciosa pesquisa com professores e familiares sobre as causas divergentes entre esses sujeitos. Os professores e professoras entrevistados no chão da escola indicaram suas suspeitas para este distanciamento que vão desde a rotatividade de professores nas escolas até as diferentes lógicas dessas instituições (SOUZA, 2017).

A ausência de participação efetiva das famílias no processo de aprendizagem das crianças resulta massivamente em problemas de organização comportamental, sinais de que os alunos se mostram muitas vezes desorientados, desorganizados, com dificuldades de internalização de regras. Quando a família é presente, é perceptível que os alunos são mais alegres, carinhosos e participativos (SOUZA, 2017). Aparentemente, a perspectiva de que os familiares devam autonomamente buscar participar da educação dos seus filhos não se trata de um fenômeno exclusivamente brasileiro como assevera a pesquisadora Maria do Sameiro Araújo (2015) da Universidade do Minho, Portugal:

[...] as dificuldades no relacionamento entre escola e família traduzem uma fonte de obstáculos ao sucesso escolar dos alunos [...]. Os pais parecem estar mais disponíveis para contatos com a escola do que a própria escola, que nem sempre potencializa essa disponibilidade. (ARAÚJO, 2015). 
Os indicativos elencados como síntese da expressão de inúmeras pesquisas científicas parecem nos trazer o fato de que muitos educadores não se dão conta de que a participação das famílias no cotidiano escolar é algo que deve ser construído, não sendo movimento natural, mas culturalmente construído. Mesmo os modelos de Joyce Epstein, Don Davies e Owen Heleen (MARQUES, 1999) focalizam a ação da família no lar e não no ambiente escolar. A ação das famílias de frequentarem as escolas das crianças de modo corriqueiro é um hábito adquirido somente por meio de um projeto de longo prazo e exige método.

Para esse fim, propomos que seja usado o termo "escola-família" em detrimento ao termo "família-escola". É preciso ficar muito claro, especialmente para os educadores, que cabe à escola conduzir os familiares dentro dessa relação (TANCREDI E REALI 2001), (REALI E TANCREDI, 2002), (CAETANO, 2004), não por uma questão hierárquica, mas "transferir essa função à família somente reforça sentimentos de ansiedade, vergonha e incapacidade aos pais, uma vez que não são eles os especialistas em educação" (CAETANO, 2004). Os gestores das redes estaduais e municipais de educação, bem como diretores e coordenadores da escola pública no Brasil, com o auxílio dos professores e professoras em sala de aula, precisam pensar e atuar para que a intencionalidade na aproximação e relação escola-família não seja só encontro, mas também seja troca, seja respeito, seja democracia o que só é possível a partir da dialogicidade. iniciar um debate a partir do elemento básico de convalidação da Família e Educação como Direitos Humanos que se interseccionam no lócus escolar.

Há alguns anos, no Brasil iniciaram-se vários movimentos pavimentados por ONGs, Associações e outros grupos afeitos ao teatro para a formação de plateia que consistia em facilitar o acesso físico aos palcos, seja por meio de subsídios que barateassem o valor das entradas até o transporte público para as instalações com incentivo governamental. Dentro dessa analogia podemos de pronto dizer que não nos interessa apenas fazer os pais das crianças irem à escola, mas fazer com que esses pais (familiares) participem de forma ativa da vida escolar, que dividam com as crianças e 
professores a descoberta do conhecimento e a socialização proporcionada pela escola ao ponto de que o termo "Comunidade Escolar" deixe de ser uma fachada terminológica que esconde um comodismo para se tornar um vocábulo carregado de experiências de transformação para todos.

Nesse sentido, a professora Ingrid Koudela (USP), pioneira na área de Pedagogia do Teatro, imaginava uma formação de espectadores que "visa não apenas à facilitação do acesso físico, mas também ao acesso aos bens simbólicos. Almeja-se inserir o espectador na história da cultura" (KOUDELA, s/d) o acesso aos bens simbólicos implica construção de conhecimento. E é isso o que ansiamos, intencionalidade: inserir as famílias na história da educação, no processo de aprendizagem de cada criança, constituindo com os familiares e com a comunidade onde se localiza cada unidade escolar uma relação cíclica e integrada que se complementem em saberes e conhecimento com uma finalidade de humanização, emancipação e cidadania de todos os sujeitos envolvidos.

\section{Considerações Finais.}

$\mathrm{O}$ respeito à singularidade de cada indivíduo, de cada criança, de cada família torna possível que escola e família estabeleçam vínculos sólidos e duradouros por meio da confiança mútua que se estabelece quando o processo de troca se manifesta com equilíbrio e intencionalidade. A história da existência humana, enquanto seres culturais, se concretiza de modo dialógico. A relação escola-família não é apenas um meio de otimizar o processo de aprendizagem das crianças, mas constitui-se como relação simbiótica de Direitos em nosso desenvolvimento cultural.

[...] De todos os contextos que nos ajudam a sermos humanos, a família fornece as condições de desenvolvimento mais importante: o amor e o cuidado que uma criança necessita para se desenvolver com sucesso. Uma criança que se transformará em um futuro adulto saudável é aquela que tem pessoas dedicadas, ativamente engajadas em sua vida - aquelas que a amam, que passam tempo com ela e estão interessadas no que ela faz e quer fazer, no que realiza no dia a dia. Outros 
contextos, como a escola, a igreja e a creche são importantes para o desenvolvimento da criança, mas ninguém pode substituir esta unidade básica do nosso sistema social: a família é o mais humano, o mais poderoso e o sistema mais econômico conhecido para tornar e manter os seres humanos mais humanos. (BRONFENBRENNER, 2011).

É na relação com o outro que nos humanizamos, é na relação com o outro que vínculos de cidadania se estabelecem e a sociedade se desenvolve de forma plural. "A arte necessita de conhecimento" (apud KOUDELA, s/d), disse Brecht, nos parece interessante ao processo de aprendizado que o conhecimento também encontre proveito em um pouco de arte ao criar um ambiente de integração e júbilo entre educadores e comunidade e não transformar a ida à escola em mais uma fardo para os pais que muitas vezes vem de uma realidade muito sofrida, mas ao invés disso, uma oportunidade para que as famílias, adultos e crianças, pais e educadores, socializem, humanizem-se, adquiram senso crítico apurado por meio do acesso ao universo escolar e da diversidade que representa a família contemporânea de modo que se fortaleçam como comunidade e como instituição social. A família não irá se dissolver no individualismo, pois somos seres imanentemente dialógicos e não existimos sem o outro.

\section{REFERÊNCIAS}

ARAÚJO, Maria Sameiro. Família, escola e sucesso escolar. Lisboa: Coisas de Ler Edições, 2015.

ARIES, Philippe. DUBY, George. História da Vida Privada Vol. 1 do Império Romano ao Ano Mil. São Paulo: Companhia de Bolso, 2009.

ARISTÓTELES. Política. Tradução (da tradução francesa) de Roberto Leal Ferreira. 2 ed. São Paulo: Martins Fontes, 1998.

BRASIL. Constituição da República Federativa do Brasil. Texto promulgado em 5 de outubro de 1988. Brasília, 1998. 
BRONFENBRENNER, U. Bioecologia do desenvolvimento humano: tornando os seres humanos mais humanos. Tradução: André de Carvalho Barreto. Revisão técnica: Sílvia H. Koller. Porto Alegre: Artmed, 2011.

CAETANO, Luciana Maria. Relação escola e família: uma proposta de parceria. 2004 Disponível em: http://www.revistaintellectus.com.br/ArtigosUpload/1.6.pdf Acessado em 01/08/2020.

DELUMEAU, Jean. ROCHE, D. (Orgs.), Histoire des pères et de la paternité. Paris: Larousse, 2000.

DESSEN, Maria Auxiliadora.; JUNIOR, Áderson Luiz Costa. A ciência do desenvolvimento humano: tendências atuais e perspectivas futuras. Porto Alegre: Artmed, 2005.

EPSTEIN, J. L.; CONNORS, L. J. A colaboração escola e família no 3. ${ }^{\circ}$ ciclo e no ensino secundário. Revista ESES, Santarém, 1992.

FLANDRIN, Jean-Louis. Familles: Parenté, maison, sexualité dans l'ancienne Société. Paris: SEUIL, 1976.

FREIRE, P. Pedagogia da autonomia: saberes necessários à prática educativa. São Paulo: Paz e Terra, 1996.

GALVÃO, I. Henri Wallon: uma concepção dialética do desenvolvimento infantil. Petrópolis: Vozes, 1995.

HÉRITIER, Françoise. Masculino. Feminino. São Paulo: Piaget, 1998.

HIGHWATER, Jamake. Mito e Sexualidade. São Paulo: Saraiva, 1992.

KOUDELA, I. A ida ao teatro. São Paulo: FDE, s/d. Disponível em: < http://culturaecurriculo.fde.sp.gov.br/administracao/Anexos/Documentos/42 0090630140316A\%20ida\%20ao\%20teatro.pdf>. Acesso em: 01/08/2020.

KUNDERA, Milan. A insustentável e leveza do ser. São Paulo: Companhia das Letras, 2017.

LÉVI-STRAUS, Claude. As estruturas elementares do parentesco. Petrópolis: Vozes, 1984.

MARQUES, R. A escola e os pais, como colaborar? Lisboa: Texto Editora, 1999. 
MAUSS, Marcel. Sociologia e antropologia. São Paulo: Cosac \& Naify, 2003.

MOUSINHO, Renata et al. Mediação escolar e inclusão: revisão, dicas e reflexões. Rev. Psicopedagogia, São Paulo, v. 27, n. 82, p. 92-108, 2010. Disponível em

\section{http://pepsic.bvsalud.org/scielo.php?script=sci_arttext\&pid=S0103-}

$\underline{84862010000100010 \& \operatorname{lng}=p t \& n r m=i s o}>$. acessos em 26 jul. 2020.

PERROT, Michele. História da Vida Privada Vol. 4 da Revolução francesa à $1^{\text {a }}$ Guerra. São Paulo: Companhia das Letras, 2009.

PIAGET, Jean. Seis estudos de psicologia. Rio de Janeiro: Forense, 1984.

POLONIA, Ana da Costa; DESSEN, Maria Auxiliadora. Em busca de uma compreensão das relações entre família escola. Psicol. Esc. Educ. (Impr.), Campinas, v. 9, n. 2, p. 303-312, Dec. 2005. Disponível em: $<$ http://www.scielo.br/scielo.php?script=sci_arttext\&pid=S1413$85572005000200012 \& \operatorname{lng}=\mathrm{en} \& n r m=i$ iso $>$. Acesso em 01/08/2020.

REALI, A. M. M. R., \& TANCREDI, R. M. S. P. (2002). Interação escola-famílias: concepções de professores e práticas pedagógicas. In M. G. N. Mizukami \& A. M. M. R. Reali (Orgs.), Formação de professores, práticas pedagógicas e escola (pp.74-98). São Carlos: EdUFSCar.

ROUDINESCO, Elizabeth. A família em desordem. Rio de Janeiro: Zahar, 2003.

SHAW. Brent D. Raising and Killing Children: Two Roman Myths. Mnemosyne. Vol. 54, Fasc. 1 (fev., 2001). Disponível em: https://www.jstor.org/stable/4433183?seq=1 Acesso em: (01/08/2020).

SOUZA, Oralda Adur de. Família-escola e desenvolvimento humano: um estudo sobre atitudes educativas familiares. Tese (Doutorado em Educação) - Programa de Pós Graduação em Educação, Universidade Federal do Paraná, Curitiba, 2017.

TANCREDI, R. M. S. P., \& REALI, A. M. M. R. (2001). Visões de professores sobre seus alunos: um estudo na área da educação infantil. Trabalho apresentado na $24^{\mathrm{a}}$ Reunião Anual da ANPEd. (pp.1-16). Caxambu. Recuperado em abril, 2006, disponível em www.anped.org.br 
TAYLOR, Charles. A Ética da Autenticidade. São Paulo: É Realizações, 2011.

THIN. Daniel. Para uma análise das relações entre famílias populares e escola: confrontação entre lógicas socializadoras. Revista Brasileira de Educação v. 11 n. 32 maio/ago. 2006

VIGOTSKY, L. S. A formação social da mente: o desenvolvimento dos processos psicológicos superiores. Tradução: José Cipolla Neto; Luis Silveira Menna Barreto; Solange Castro Afeche. 6. ed. São Paulo: Martins Fontes, 1998a.

VIGOTSKY, L. S. O desenvolvimento psicológico na infância. Tradução: Claudia Berliner. São Paulo: Martins Fontes, 1998b. São Paulo: Martins Fontes, 1998a.

Submetido em: $21 / 08 / 2020$

Aceito em: $27 / 08 / 2020$

Publicado em: $30 / 08 / 2020$ 